\title{
Pulmonary Hypertension with Valvular Heart Disease: When to Treat the Valve Disease and When to Treat the Pulmonary Hypertension
}

\author{
Christophe Martinez ${ }^{1} \cdot$ Toshimitsu Tsugu $^{1}$ (D) $\cdot$ Tadafumi Sugimoto $^{2}$ (i) $\cdot$ Patrizio Lancellotti $^{1,3}$ (i)
}

Published online: 25 November 2019

(C) Springer Science+Business Media, LLC, part of Springer Nature 2019

\begin{abstract}
Purpose of Review This article will review the current guidelines for therapeutic intervention in (pulmonary hypertension) $\mathrm{PH}$ related to left heart disease (PH-LHD).

Recent Findings The 6th World Symposium on Pulmonary Hypertension (WSPH) recommended that the mean pulmonary artery pressure (mPAP) should be lowered to $20 \mathrm{mmHg}$. In several randomized controlled trials performed in patients with PH-LHD, pulmonary arterial hypertension (PAH)-specific drug therapy demonstrated no evidence of beneficial effects. Furthermore, in the sildenafil for improving outcomes after valvular correction (SIOVAC) trial, the use of sildenafil in the context of PH post-valvular heart disease (VHD) intervention is associated with an increased risk of clinical deterioration and death. Therefore, medical therapy such as PAH-specific drugs is still not recommended in PH-LHD. The principle of PH-LHD therapy is the treatment of underlying VHD. It is crucial to undergo surgical intervention at an appropriate time prior the development of potentially irreversible PH. Stress echocardiography (SE) is helpful to define symptoms and can be useful to assess the systolic pulmonary artery pressure (SPAP) and stratify severity of VHD.

Summary This comprehensive review of the literature highlights the role of SE imaging to assess VHD and is needed for the asymptomatic patients with severe VHD or symptomatic patients with non-severe VHD in the context of PH-LHD. The focus of patient evaluation should be on identifying patients with significant underlying valvular heart disease and referring in a timely manner for VHD treatment per society guidelines as pharmacologic pulmonary vasodilator therapy for PH-LHD has not shown efficacy as seen in other forms of PH.
\end{abstract}

Keywords Valvular heart disease $\cdot$ Surgery $\cdot$ Stress echocardiography $\cdot$ Aortic stenosis $\cdot$ Mitral stenosis $\cdot$ Mitral regurgitation

This article is part of the Topical Collection on Valvular Heart Disease

Patrizio Lancellotti

plancellotti@chu.ulg.ac.be

Christophe Martinez

cmartinez@chu.ulg.ac.be

Toshimitsu Tsugu

tsugu917@gmail.com

Tadafumi Sugimoto

t_sugimoto_japan@hotmail.com

1 Department of Cardiology, University of Liège Hospital, GIGA Cardiovascular Sciences, CHU du Sart Tilman, Université de Liège, 4000 Liège, Belgium

2 Clinical Laboratory, Mie University Hospital, Mie, 2-174 Edobashi, Tsu, Japan

3 Gruppo Villa Maria Care and Research, Anthea Hospital, Bari, Italy

\section{Introduction}

According to the guidelines of European Society of Cardiology (ESC)/European Respiratory Society (ERS), pulmonary hypertension $(\mathrm{PH})$ is defined as an increase in mean pulmonary arterial pressure (mPAP) $\geq 25 \mathrm{mmHg}$ at rest as assessed by right heart catheterization (RHC) [1]. Recently, it was suggested that the mPAP threshold should be lowered to $20 \mathrm{mmHg}$ at the 6th World Symposium on Pulmonary Hypertension (WSPH) in Nice, 2018 [2]. This suggestion is based on data from healthy subjects in whom the normal $\mathrm{mPAP}$ at rest is $14 \pm 3 \mathrm{mmHg}$ with an upper limit of approximately $20 \mathrm{mmHg}[3,4]$. Two standard deviations above this mean value would indicate that a $\mathrm{mPAP}>20 \mathrm{mmHg}$ is the threshold for abnormal pulmonary arterial pressure (above the 97.5th percentile). However, mPAP of $20 \mathrm{mmHg}$ alone is not sufficient to cause pulmonary vascular disease. Therefore, the task force has proposed including a pulmonary vascular resistance (PVR) $\geq 3$ Wood units (WU) into the definition [2]. The 
definition of PH may change in the future; we will consider it in line with the current guidelines and the 6th WSPH recommendations.

\section{Mechanism of Development of Pulmonary Hypertension Due to VHD}

In severe valvular heart disease (VHD), a progressive increase in left ventricular (LV) filling pressure and left atrial (LA) pressure leads to a corresponding passive increase in pressure in the pulmonary veins and, subsequently, to isolated postcapillary PH (Ipc-PH), which can still be reversible at this stage. However, when pulmonary vasoconstriction or vascular remodeling ensues with Ipc-PH, $\mathrm{PH}$ may become irreversible and is called combined post-capillary $\mathrm{PH}(\mathrm{Cpc}-\mathrm{PH})$. Cpc-PH occurs in 12 to $13 \%$ of patients with $\mathrm{PH}$ due to left heart disease (Fig. 1).

\section{Definition}

In the ESC/ERS guidelines, $\mathrm{PH}$ related to left heart disease (PH-LHD) is classified into group $2 \mathrm{PH}$ with subgroup 2.3 specifically dedicated to VHD. A definitive diagnosis of $\mathrm{PH}-$ LHD is made when the mPAP $\geq 25 \mathrm{mmHg}$ with a pulmonary artery wedge pressure (PAWP) $>15 \mathrm{mmHg}$ in the context of significant VHD [1,5]. Ipc-PH is defined as a diastolic pulmonary pressure gradient (DPG: diastolic pulmonary artery pressure minus mean PAWP) $<7 \mathrm{mmHg}$ and/or PVR $\leq$ 3 WU. An out-of-portion increase in the mPAP with respect to the PAWP suggestive of pulmonary vascular remodeling and constriction defines Cpc-PH (DPG is $\geq 7 \mathrm{mmHg}$ and/or PVR is $>3 \mathrm{WU}$ ) $[1,5,6]$ (Fig. 1).

In contrast, new defining criteria for the different hemodynamic types of $\mathrm{PH}$ that occur with LHD have been proposed by the 6th World Symposia on Pulmonary Hypertension (WSPH) [7•]. The proposed hemodynamic definition of PHLHD by the WSPH is based only on hemodynamic right heart catheterization (RHC) values: (1) Ipc-PH: PAWP $>15 \mathrm{mmHg}$ and $\mathrm{mPAP}>20 \mathrm{mmHg}$ and PVR $<3 \mathrm{WU}$; (2) Cpc-PH: PAWP $>15 \mathrm{mmHg}$ and $\mathrm{mPAP}>20 \mathrm{mmHg}$ and PVR $\geq 3 \mathrm{WU}$.

\section{Diagnosis}

Clinical signs and symptoms of PH-LHD are orthopnea and paroxysmal nocturnal dyspnea, which are generally not features of other types of PH [8]. Signs of right ventricular heart failure, such as peripheral edema, ascites, and syncope, depend on the severity of PH-LHD. These additional findings suggest the presence of PH-LHD: pulmonary vascular congestion, pleural effusion, and/or pulmonary edema on chest $\mathrm{X}$-ray or computed tomography. In addition to the right ventricular overload findings, LV/LA hypertrophy is a distinctive sign on echocardiogram. RHC is mandatory for the

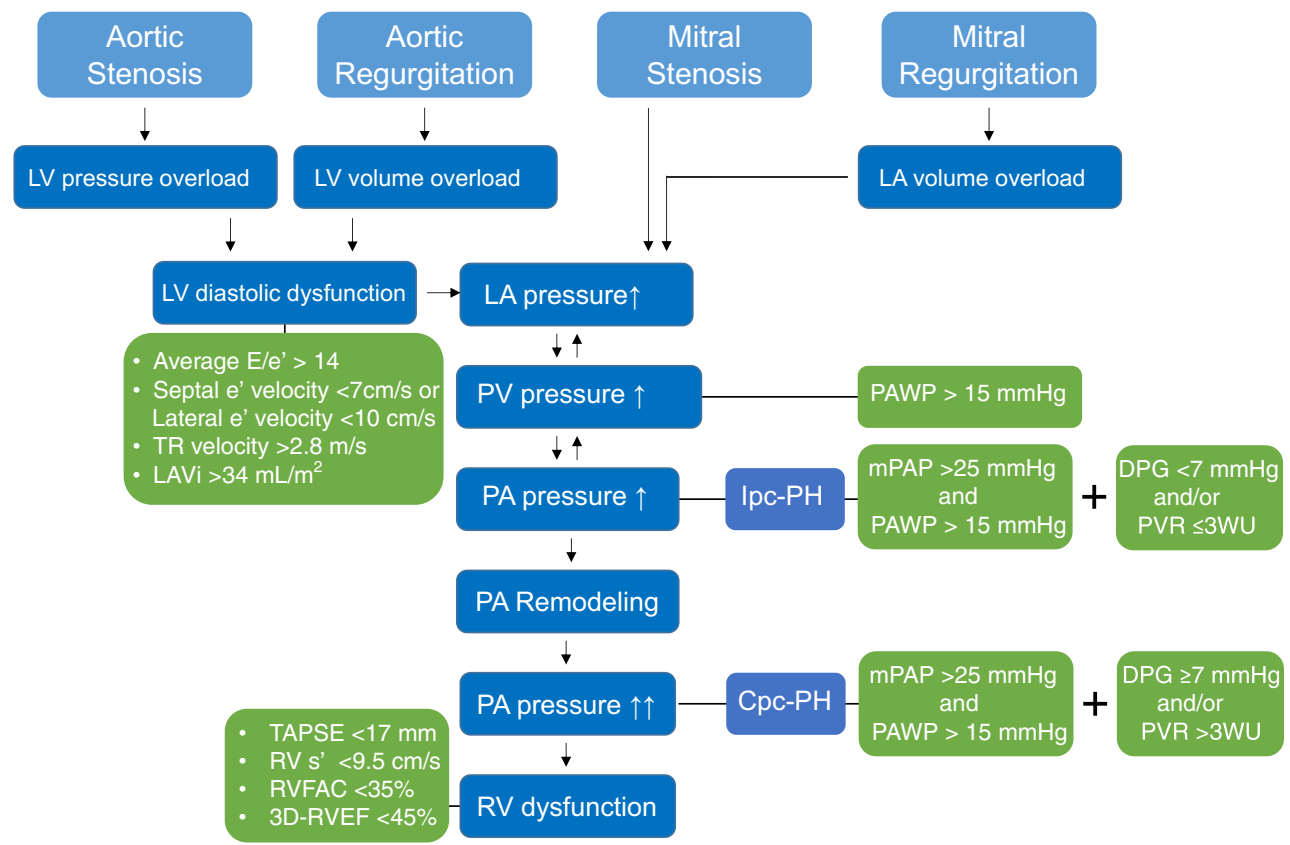

Fig. 1 Mechanisms for development of pulmonary hypertension due to valvular heart disease. $L V$ left ventricular; $L A$ left atrial; $T R$ tricuspid regurgitation; $L A V i$ left atrial volume index; TAPSE tricuspid annular plane excursion; $R V F A C$ right ventricular fractional area change; $3 D$ $R V E F$ three-dimensional RVEF; $P V$ pulmonary vein; $P A$ pulmonary artery; $R V$ right ventricular; $I p c-P H$ isolated post-capillary pulmonary hypertension; $C p c-P H$ combined pre- and post-capillary pulmonary hypertension; $M P A P$ mean pulmonary artery pressure; $P A W P$ pulmonary artery wedge pressure; $D P G$ diastolic pulmonary gradient; $P V R$ pulmonary vascular resistance; $W U$ Wood units 
confirmation of a $\mathrm{PH}$ diagnosis. Echocardiography also plays an important role not only for the diagnosis of $\mathrm{PH}$ but also for the identification of and characterization of VHD severity. A probability model for PH-LHD (low, intermediate, high) was published in the 6th WSPH (Table 1) [7•]. This pre-test probability matrix may aid in correct classification of PH-LHD for patients with suspected $\mathrm{PH}$.

\section{Resting Echocardiography}

Transthoracic echocardiography (TTE) is the initial evaluation modality for patients with suspected $\mathrm{PH}$ of any etiology and is particularly informative for cases of suspected PH-LHD. TTE can estimate systolic pulmonary artery pressure (SPAP) noninvasively via Doppler ultrasound evaluation. The SPAP is the sum of right ventricular + right atrial pressure. The most commonly used technique to estimate SPAP remains the direct measurement of peak tricuspid regurgitation jet velocity

Table 1 Probability of pulmonary hypertension related to LHD (Reproduced with permission of the (C) ERS 2019: European Respiratory Journal 53 (1) 1801897; https://doi.org/10.1183/13993003. 01897-2018 Published 24 January 2019) [7•]

\begin{tabular}{|c|c|c|c|}
\hline Feature & $\begin{array}{l}\text { Low } \\
\text { probability }\end{array}$ & $\begin{array}{l}\text { Intermediate } \\
\text { probability }\end{array}$ & $\begin{array}{l}\text { High } \\
\text { probability }\end{array}$ \\
\hline Age & $<60$ years & $60-70$ years & $>70$ years \\
\hline $\begin{array}{l}\text { Obesity, systemic } \\
\text { hypertension, } \\
\text { glucose } \\
\text { intolerance/diabetes }\end{array}$ & None & $1-2$ factors & $>2$ factors \\
\hline $\begin{array}{l}\text { Previous cardiac } \\
\text { intervention* }\end{array}$ & No & No & Yes \\
\hline Atrial fibrillation & No & Paroxysmal & Current \\
\hline Structural LHD & No & No & Present \\
\hline ECG & $\begin{array}{l}\text { Normal or } \\
\text { signs of } \\
\text { RV strain }\end{array}$ & Mild LVH & LBBB or LVH \\
\hline Echocardiography & $\begin{array}{l}\text { No LA } \\
\text { dilatation; } \\
E / e^{\prime}<13\end{array}$ & $\begin{array}{l}\text { No LA } \\
\text { dilatation; } \\
\text { grade }<2 \\
\text { mitral flow }\end{array}$ & $\begin{array}{l}\text { LA dilatation; } \\
\text { grade }>2 \\
\text { mitral flow }\end{array}$ \\
\hline CPET & $\begin{array}{l}\text { High } V^{\prime} E / V^{\prime} \\
\mathrm{CO}_{2} \text { slope; } \\
\text { no EOV }\end{array}$ & $\begin{array}{l}\text { Elevated } V^{\prime} \\
E / V^{\prime} \mathrm{CO}_{2} \\
\text { slope or } \\
\text { EOV }\end{array}$ & $\begin{array}{l}\text { Mildly } \\
\text { elevated } \\
V E / V \mathrm{CO}_{2} \\
\text { slope; } \mathrm{EOV}\end{array}$ \\
\hline CMR & $\begin{array}{l}\text { No left heart } \\
\text { abnormali- } \\
\text { ties }\end{array}$ & & $\begin{array}{l}\text { LA strain or } \\
\text { LA/RA > } 1\end{array}$ \\
\hline
\end{tabular}

*Coronary artery and/or valvular surgical and/or surgical producers, including percutaneous interventions

$C P E T$ cardiopulmonary exercise testing, $C M R$ cardiac magnetic resonance, $E O V$ exercise oscillatory ventilation, $L A$ left atrial, $L B B B$ left bundle branch block, $L H D$ left heart disease, $L V H$ left ventricular hypertrophy, $R A$ right atrial, $R V$ right ventricular, $V^{\prime} \mathrm{CO}_{2}$ carbon dioxide production, $V^{\prime} E$ minute ventilation which, when applied to the simplified Bernoulli equation (peak gradient $=4 v^{2}$ ), provides the estimated RV pressure. A tricuspid regurgitation jet velocity $<2.5 \mathrm{~m} / \mathrm{s}$ is considered to be normal, $2.5-2.8 \mathrm{~m} / \mathrm{s}$ as borderline, and $>2.8 \mathrm{~m} / \mathrm{s}$ as strongly indicative for manifest $\mathrm{PH}$. The right atrial pressure may be derived from the assessment of the inferior vena cava diameter (measured with the patient in the left decubitus position at 1.0 to $2.0 \mathrm{~cm}$ from the junction with the right atrium) and its respiratory changes [8]. In addition, it also provides visual assessment of the RV size and function related to potential $\mathrm{PH}$.

Furthermore, in cases of suspected PH-LHD, TTE can characterize the severity of valve lesions. The various valve pathologies will be discussed in greater detail below.

\section{Stress Echocardiography}

The clinical indications for stress echocardiography (SE) in the context of PH-LHD are as follows: severe VHD without symptoms, non-severe VHD with symptoms, and symptomatic non-severe VHD with low flow [9-11]. Heart rate normally increases two- to three-fold during exercise, contractility three- to four-fold, and systolic blood pressure by $\geq 50 \%$, while systemic vascular resistance decreases. This often serves to reveal symptoms in patients previously considered asymptomatic or, for example, may demonstrate that mitral valve stenosis changes from moderate to severe with activity. Therefore, SE may be a useful diagnostic tool in selected cases of suspected PH-LHD leading to recommendations to treat the underlying VHD.

\section{Therapy}

There are three effective therapeutic options for PH-LHD: (1) surgical/interventional treatment; (2) non-specific pulmonary arterial hypertension (PAH) drugs; and (3) PAH-specific drugs. Indications for invasive therapy, surgery or transcatheter treatment, depend on the VHD etiology (see below). Some patients may benefit from non-specific vasodilators such as nitrates and hydralazine, although evidence supporting this approach is limited [12, 13]. PAH-specific drugs such as endothelin receptor antagonists and phosphodiesterase-5 inhibitors have been reported to be effective in terms of improvement in hemodynamics, exercise tolerance, and symptoms, but these results did not provide enough evidence to support the use of these drugs [13]. The sildenafil for improving outcomes after valvular correction (SIOVAC) trial was performed to determine whether treatment with sildenafil improved outcomes of patients with $\mathrm{PH}$ after correction of VHD. Patients underwent a successful surgical treatment (valve replacement or repair) during the year before enrollment and were randomized to $40 \mathrm{mg}$ sildenafil three times daily versus 
placebo for 6 months. The primary endpoint was a composite clinical score combining death, hospital admission for heart failure, change in New York Heart Association functional class, and patient global self-assessment. Improvement in the clinical score was significantly more frequent in the placebo group. In contrast, worsening of the clinical score was more common in the sildenafil group [14]. There is still no multicenter trial that suggests targeting PH-LHD with PAH-specific drugs is beneficial, and the 6th WSPH does not recommend the use of PAH-specific drugs in the treatment of group $2 \mathrm{PH}$ $[7 \cdot]$.

\section{Aortic Stenosis}

Resting PH has been reported in up to $15-30 \%$ of patients with severe symptomatic aortic stenosis (AS) [15], whereas the prevalence of $\mathrm{PH}$ in patients with asymptomatic severe AS patients is about $6 \%$ [16]. The negative impact on outcome of $\mathrm{PH}$ has been largely demonstrated in patients with symptomatic AS. Conversely, data are limited in asymptomatic AS. In our previously published data, asymptomatic patients with resting PH were older and had greater severity of AS, and half of them experienced cardiac events during the follow-up (including 1 death and 2 aortic valve replacements prompted by development of severe symptoms) [16]. The presence of PH in reportedly asymptomatic patients should raise suspicion about occult or unrecognized symptoms that would potentially trigger referral for valve replacement. Surgery is indicated in symptomatic patients with severe AS (ESC/EACTS and

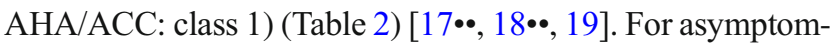
atic patients with severe AS, the ESC/EACTS guidelines recommend surgery when the left ventricular ejection fraction (LVEF) is $<50 \%$, in cases with symptoms (class 1 ) or a decrease in systolic blood pressure (class IIa) during exercise testing, or when a PH (SPAP $>60 \mathrm{mmHg}$ ) (class IIa) is confirmed at RHC. SE has recently emerged as a potential tool to better stratify the risk of patients with asymptomatic AS. Lancellotti et al. showed that exercise PH (SPAP > $60 \mathrm{mmHg}$ ), observed in $55 \%$ of asymptomatic patients with severe AS, was independently associated with a 2 -fold increase in risk of cardiac events [16]. The development of PH at exercise was mainly determined by male gender, resting SPAP, LV parameters of diastolic burden during exercise (i.e. LV end-diastolic volume, left atrial area and $e^{\prime}$-wave velocity), and aortic valve area compliance (higher mean transaortic gradient). In practice, an increase in mean aortic pressure gradient $(>18-20 \mathrm{mmHg}$ ), a deterioration of LV systolic function, the lack of LV contractile reverse, and a SPAP $>60 \mathrm{mmHg}$ during $\mathrm{SE}$ are strong predictors of worse prognosis in patients with asymptomatic AS [20]. Patients with exercise $\mathrm{PH}$ require closer follow-up to rapidly identify the onset of symptoms or any changes in LV function. When peak aortic jet velocity is $>4 \mathrm{~m} / \mathrm{s}$ and exercise $\mathrm{PH}$ is observed, a high rate of cardiac-related death is observed in these patients $(12 \%)$. While interesting from a research and prognosis perspective, exercise-induced PH is not included in the ACC/AHA or ESC valve guideline recommendations for aortic valve replacement. The potential role for exercise-induced $\mathrm{PH}$ to trigger aortic valve replacement may be studied in future prospective large-scale clinical studies.

\section{Mitral Stenosis}

Percutaneous mitral balloon commissurotomy (PMC) is indicated in symptomatic patients with moderate or severe mitral stenosis (MS) (mitral valve area $\leq 1.5 \mathrm{~cm}^{2}$ ), whereas mitral valve surgery is indicated in symptomatic patients who are not suitable for PMC (AHA/ACC and ESC/EACTS: class I) $[18 \bullet \bullet, 19]$. PMC should also be considered per the ESC guidelines in asymptomatic patients at high risk of hemodynamic decompensation (SPAP $>50 \mathrm{mmHg}$ at rest) [18••].

$\mathrm{SE}$ is recommended for the assessment of patients with both asymptomatic severe MS and symptomatic non-severe MS. The AHA/ACC guidelines do not define an elevated SPAP in the evaluation/management algorithm but rather utilize a PCWP $>25 \mathrm{mmHg}$ with exercise as a class IIb recommendation for PMC. However, a rise in SPAP to $>60$ $70 \mathrm{mmHg}$ should prompt the clinician to carefully consider the patient's symptoms (class I) [19]. EACVI/ASE recommends to consider PMC if exertion results in a mean gradient $>15 \mathrm{mmHg}$ and SPAP $>60 \mathrm{mmHg}$ [20].

The previous criteria are for rheumatic MS (RMS) but MS has not only RMS but also degenerative MS (DMS). The majority of MS is RMS, which is an inflammatory change affected by rheumatic fever, although its frequency has significantly decreased in industrialized countries [21]. DMS is characterized by chronic non-inflammatory degeneration and subsequent calcification of the fibrous mitral annulus and the mitral valve leaflets, often referred to as mitral annular calcification. The accurate prevalence of DMS in the general population is unknown, but the prevalence is increasing with the aging of the population. In a large retrospective cohort study, the mean age of patients with DMS was $73 \pm 14$ years and SPAP $\geq$ $40 \mathrm{mmHg}$ was found in $63 \%$. The 5 -year mortality rate of $53 \%$ due to DMS was three times the expected mortality in the US general population [22]. Although RMS and DMS should be considered quite different pathological conditions, they are evaluated using the same criteria in the current guidelines. However, one should keep in mind that decision-making may be more challenging in DMS patients. Surgery for DMS is higher risk as it occurs in elderly patients with a severely calcified mitral annulus. Noteworthy, most of these patients have coronary artery 
Table 2 Summary of the AHA/ACC and ESC/EACTS guidelines for rest and stress echocardiographic indications for the surgery in VHD

\begin{tabular}{|c|c|c|c|c|c|c|}
\hline \multirow[t]{2}{*}{ VHD } & \multirow[t]{2}{*}{ Clinical status } & \multicolumn{2}{|l|}{ Moderate } & \multicolumn{2}{|l|}{ Severe } & \multirow[b]{2}{*}{$\begin{array}{l}\text { EACVI/ASE } \\
\text { recommendation }\end{array}$} \\
\hline & & $\begin{array}{l}\text { 2014/2017 ACC/AHA } \\
\text { guidelines for surgery }\end{array}$ & $\begin{array}{l}2017 \mathrm{ESC} / \mathrm{EACTS} \\
\text { guidelines for surgery }\end{array}$ & $\begin{array}{l}\text { 2014/2017 ACC/AHA } \\
\text { guidelines for surgery }\end{array}$ & $\begin{array}{l}2017 \text { ESC/EACTS } \\
\text { guidelines for surgery }\end{array}$ & \\
\hline \multirow[t]{2}{*}{ AS } & Symptomatic & $\begin{array}{l}\text { SE: evaluate the } \\
\text { low-flow/low-- } \\
\text { gradient AS with } \\
\text { LVEF < 50\% (class } \\
\text { 2a) }\end{array}$ & $\begin{array}{l}\text { Patients with mild } \\
\text { and moderate AS } \\
\text { should be } \\
\text { re-evaluated year- } \\
\text { ly. }\end{array}$ & $\begin{array}{l}\text { SE: contraindication } \\
\text { (class 3) }\end{array}$ & SE: contraindication & SE: contraindication \\
\hline & Asymptomatic & None & & $\begin{array}{l}\text { Rest: } \mathrm{LVEF}<50 \% \\
\quad \text { (class } 1 \text { ) or very } \\
\text { severe (aortic } \\
\text { velocity } \geq 5.0 \mathrm{~m} / \mathrm{s} \text { ) } \\
\text { and low surgical } \\
\text { risk } \\
\text { SE: decrease exercise } \\
\text { tolerance or } \\
\text { exercise fall in BP } \\
\text { (class } 2 \mathrm{a} \text { ) }\end{array}$ & $\begin{array}{l}\text { Rest: LVEF < } 50 \% \\
\text { (class 1) } \\
\text { SE: symptoms (class } \\
\text { 1), decrease in BP } \\
\text { below baseline } \\
\text { (class 2a), SPAP } \\
>60 \mathrm{mmHg} \text { (class } \\
\text { 2a) }\end{array}$ & $\begin{array}{l}\text { SE: increase in } \mathrm{mPG} \\
>18-20 \mathrm{mmHg}, \\
\text { SPAP }>60 \mathrm{mmHg}, \\
\text { lack of LV } \\
\text { contractile reserve, } \\
\text { and deterioration of } \\
\text { LV systolic function } \\
\text { are predictors of } \\
\text { worse prognosis }\end{array}$ \\
\hline $\begin{array}{c}\text { Rheumatic } \\
\text { MS }\end{array}$ & $\begin{array}{l}\text { Symptomatic } \\
\text { Asymptomatic }\end{array}$ & $\begin{array}{l}\text { SE: evaluate the } \\
\text { response of mPG } \\
\text { and SPAP when } \\
\text { there is a } \\
\text { discrepancy } \\
\text { between TTE } \\
\text { findings and clinical } \\
\text { symptoms (class 1). } \\
\text { Note the symptoms } \\
\text { when SPAP } \\
>60-70 \mathrm{mmHg}\end{array}$ & $\begin{array}{l}\text { SE: provide } \\
\text { additional } \\
\text { information by } \\
\text { assessing change in } \\
\text { mPG and SPAP }\end{array}$ & $\begin{array}{l}\text { Rest: MVA } \leq 1.5 \mathrm{~cm}^{2} \\
\quad \text { (class } 1) \\
\text { Rest: very severe } \\
\quad\left(\mathrm{MVA} \leq 1.0 \mathrm{~cm}^{2}\right)\end{array}$ & $\begin{array}{l}\text { Rest: MVA } \leq 1.5 \mathrm{~cm}^{2} \\
\quad \text { (class 1) } \\
\text { Rest: SPAP } \\
>50 \mathrm{mmHg} \text { (class } \\
\text { 2a) } \\
\text { SE: } \mathrm{mPG}>15 \mathrm{mmHg} \\
\quad \text { and SPAP } \\
>60 \mathrm{mmHg}\end{array}$ & $\begin{array}{l}\text { SE: patients should be } \\
\text { considered severe } \\
\text { when } \mathrm{mPG} \\
>15 \mathrm{mmHg} \text { and } \\
\text { SPAP }>60 \mathrm{mmHg}\end{array}$ \\
\hline $\begin{array}{c}\text { Primary } \\
\text { MR }\end{array}$ & $\begin{array}{l}\text { Symptomatic } \\
\text { Asymptomatic }\end{array}$ & $\begin{array}{l}\text { SE: evaluate the } \\
\text { response of } \\
\text { symptoms when } \\
\text { there is a } \\
\text { discrepancy } \\
\text { between symptoms } \\
\text { and severity of MR } \\
\text { at rest (class } 2 \mathrm{a} \text { ) }\end{array}$ & $\begin{array}{l}\text { Patients with } \\
\text { moderate MR and } \\
\text { preserved LVEF } \\
\text { can be followed on } \\
\text { a yearly basis and } \\
\text { echocardiography } \\
\text { should be } \\
\text { performed every } \\
1-2 \text { years. }\end{array}$ & $\begin{array}{l}\text { Rest: LVEF > 30\% } \\
\text { (class 1) } \\
\text { Rest: LV dysfunction } \\
\text { (LVESD } \geq 40 \mathrm{~mm} \\
\text { and/or LVEF } \\
\text { 30-60\%) (class 1), } \\
\text { preserved LV func- } \\
\text { tion (LVESD } \\
<40 \mathrm{~mm} \text { and LVEF } \\
>60 \% \text { ) and new } \\
\text { onset of AF or } \\
\text { SPAP > 50 mmHg } \\
\text { (class } 2 \mathrm{a} \text { ) }\end{array}$ & $\begin{array}{l}\text { Rest: LVEF }>30 \% \\
\text { (class 1) } \\
\text { Rest: LV dysfunction } \\
\text { (LVESD } \geq 45 \mathrm{~mm} \\
\text { and/or LVEF } \\
\leq 60 \% \text { ) (class 1), } \\
\text { preserved LV func- } \\
\text { tion (LVESD } \\
<45 \mathrm{~mm} \text { and LVEF } \\
>60 \% \text { ) and new } \\
\text { onset of AF or } \\
\text { SPAP > 50 mmHg } \\
\text { (class } 2 \mathrm{a} \text { ) }\end{array}$ & $\begin{array}{l}\text { SE: increase in MR } \\
\text { severity ( } \geq 1 \text { grade), } \\
\text { SPAP } \geq 60 \mathrm{mmHg}, \\
<5 \% \text { increase in EF } \\
\text { or }<2 \% \text { increase in } \\
\text { GLS, and TAPSE } \\
<19 \mathrm{~mm} \text { are } \\
\text { predictors of worse } \\
\text { prognosis }\end{array}$ \\
\hline $\begin{array}{l}\text { Secondary } \\
\text { MR }\end{array}$ & Symptomatic & $\begin{array}{l}\text { Rest: undergoing other } \\
\text { cardiac surgery }\end{array}$ & & $\begin{array}{l}\text { Rest: severely } \\
\text { symptoms (NYHA } \\
\text { 3/4) (class 2b) }\end{array}$ & $\begin{array}{l}\text { Rest: LVEF }<30 \% \text { but } \\
\text { with an option for } \\
\text { revascularization } \\
\text { and evidence of } \\
\text { myocardial viability } \\
\text { (2a) }\end{array}$ & $\begin{array}{l}\text { Increase in ERO } \\
\geq 13 \mathrm{~mm}^{2} \text { and } \\
\mathrm{SPAP} \geq 60 \mathrm{mmHg} \\
\text { are predictors of } \\
\text { worse prognosis }\end{array}$ \\
\hline & Asymptomatic & & None & None & None & \\
\hline
\end{tabular}

AHA American Heart Association, ACC American College of Cardiology, ESC European Society of Cardiology, EACTS European Association For Cardio-Thoracic Surgery, EACVI European Association of Cardiovascular Imaging, ASE American Society of Echocardiography, VHD valvular heart disease, $A S$ aortic stenosis, $M S$ mitral stenosis, $M R$ mitral regurgitation, $S E$ stress echocardiography, $L V E F$ left ventricular ejection fraction, $B P$ blood pressure, $S P A P$ systolic pulmonary artery pressure, $M V A$ mitral valve area, $m P G$ mean pressure gradient, $L V E S D$ left ventricular end-systolic diameter, GLS global longitudinal strain, NYHA New York Heart Association, ERO effective regurgitation orifice

disease (49\%). PMC is also higher risk in cases of DMS due to the unique feature of no commissural fusion [23]. In patients with severe DMS, preliminary experience has been reported with transcatheter valve replacement [24].

\section{Primary Mitral Regurgitation}

The prevalence of $\mathrm{PH}$ in mitral regurgitation (MR) varies according to symptomatic status, MR severity, and the presence 
of LV systolic dysfunction [25-28]. Resting PH (SPAP > $50 \mathrm{mmHg}$ ) is present in $20-30 \%$ of patients with severe MR and up to $64 \%$ in severely symptomatic patients [29]. Surgery, especially repair, is the standard of care for primary degenerative MR and is indicated (class I) for all patients with either symptoms or LV dilation/dysfunction (LVESD $\geq 40 \mathrm{~mm}$ and/or $\mathrm{LVEF} \geq 30-60 \%$ for ACC/AHA; LVESD $\geq 45 \mathrm{~mm}$ and/or

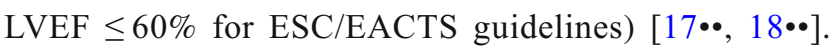
Percutaneous edge-to-edge repair (MitraClip) may also be considered (class IIb) in patients with symptomatic severe primary MR who fulfill the echocardiographic criteria of eligibility and are judged inoperable or at high surgical risk by the Heart Team $\left[18^{\circ}\right]$. Surgical mitral valve repair should also be considered (class IIa) in asymptomatic patients with severe MR, preserved $\mathrm{LV}$ function (LVESD $<45 \mathrm{~mm}$ and $\mathrm{LVEF}>60 \%$ for $\mathrm{ESC} /$ EACTS guidelines), and either new onset of atrial fibrillation or resting $\mathrm{PH}(\mathrm{SPAP} \geq 50 \mathrm{mmHg}$ ) (ACC/AHA [17••] and $\mathrm{ESC} /$ EACTS [18••] guidelines). The low SPAP threshold associated with outcome supports that surgery should not be delayed in the presence of significant PH. Nevertheless, waiting for SPAP to progress $\geq 50 \mathrm{mmHg}$ to treat MR may impact prognosis and persistent postoperative $\mathrm{PH}$ [26].

Surgery (ESC/EACTS) should be considered in asymptomatic patients with preserved LVEF (>60\%) and LVESD 40$44 \mathrm{~mm}$ when a durable repair is likely, surgical risk is low, the repair is performed in heart valve centers, and the following finding is present: flail leaflet or presence of significant LA dilatation (volume index $\geq 60 \mathrm{~mL} / \mathrm{m}^{2} \mathrm{BSA}$ ) in sinus rhythm. In the ACC/AHA guidelines, mitral valve repair is also a class IIa in asymptomatic patients with chronic severe primary MR with preserved LV function (LVEF $>60 \%$ and LVESD $<40 \mathrm{~mm}$ ) in whom the likelihood of a successful and durable repair without residual $\mathrm{MR}$ is $>95 \%$ with an expected mortality rate of $<1 \%$ when performed at a Heart Valve Center of Excellence. The imaging group (EACVI/ASE) recommends exercise echocardiography to provoke symptoms and to assess the SPAP, with an increase by $\geq 1$ grade in MR, a SPAP $\geq 60 \mathrm{mmHg}$, and a lack of contractile reverse $(<5 \%$ increase in $\mathrm{EF}$ or $<2 \%$ increase in global longitudinal strain) during exercise reported as markers of poor prognosis [20]. Whether exercise echocardiography results may help in decision-making and ultimately improve patient outcomes requires further analysis.

\section{Secondary Mitral Regurgitation}

Patients with chronic secondary MR and heart failure with reduced LVEF should receive standard guideline-directed medical therapy for heart failure, including ACE inhibitors, ARBs, beta-blockers, and/or aldosterone antagonists, and cardiac resynchronization therapy (CRT) as indicated. Mitral valve surgery is reasonable for patients with chronic severe secondary MR who are undergoing coronary artery bypass grafting (CABG) or AVR (ACC/AHA class IIa). Conversely, surgery is a class I indication in the ESC/EACTS guidelines in patients with severe MR and LVEF > 30\% undergoing CABG. Mitral valve repair or replacement may be considered (class IIb) for severely symptomatic patients with chronic severe secondary MR who have persistent symptoms despite optimal medical therapy, including CRT if indicated, for heart failure $[17 \bullet \bullet, 18 \bullet \bullet]$.

In patients with severe secondary MR and LVEF $<30 \%$ who remain symptomatic despite optimal med management (including CRT if indicated) and who have no option for revascularization, the Heart Team may also consider a percutaneous edgeto-edge procedure (MitraClip) (ESC/EACTS class IIb). No similar consideration is made in the ACC/AHA guidelines. However, this is subject to change due to the recent results from the COAPT trial comparing a percutaneous mitral valve repair therapy (using a MitraClip device) plus medical therapy with medical therapy alone in carefully selected heart failure patients with reduced LVEF and more than moderate secondary MR. The absolute risk reduction in all-cause mortality in patients receiving the MitraClip in the COAPT trial was $17 \%$ which translated to a number needed to treat $(\mathrm{NNT})$ of 6 to prevent one death over 2 years [30]. The US FDA approved use of the MitraClip device for secondary MR in March 2019.

\section{Conclusions}

The focus of PH-LHD therapy relates to the treatment of underlying VHD. PAH non-specific or specific drugs do not demonstrate clinical benefit in PH-LHD, and the 6th WSPH recommends against the use of PAH-specific drugs in PH-LHD. Ipc-PH proceeds over time to Cpc$\mathrm{PH}$, which represents an irreversible change. Therefore, treatment for VHD should be ideally pursued before the Cpc-PH stage. In patients with severe VHD, the onset of symptoms is a clear indication for intervention (surgery or transcatheter). Treatment decision in asymptomatic patients with severe VHD or in symptomatic with moderate VHD remains challenging. The role of $\mathrm{PH}$ in the management of VHD depends on the valve pathology involved with greater evidence for using the presence of $\mathrm{PH}$ with mitral valve regurgitation to recommend valve surgery in the society guidelines. Future research will hopefully provide additional data on the role of $\mathrm{PH}$ in the timing of VHD treatment leading to better patient outcomes.

\section{Compliance with Ethical Standards}

Conflict of Interest Christophe Martinez, Toshimitsu Tsugu, Tadafumi Sugimoto, and Patrizio Lancellotti declare that they have no conflict of interest. 
Human and Animal Rights and Informed Consent This article does not contain any studies with human or animal subjects performed by any of the authors.

\section{References}

Papers of particular interest, published recently, have been highlighted as:

- Of importance

•- Of major importance

1. Galie N, Humbert M, Vachiery JL, et al. 2015 ESC/ERS guidelines for the diagnosis and treatment of pulmonary hypertension: the Joint Task Force for the Diagnosis and Treatment of Pulmonary Hypertension of the European Society of Cardiology (ESC) and the European Respiratory Society (ERS): endorsed by: Association for European Paediatric and Congenital Cardiology (AEPC), International Society for Heart and Lung Transplantation (ISHLT). Eur Heart J. 2016;37:67-119.

2. Galie N, McLaughlin VV, Rubin LJ, et al. An overview of the 6th World Symposium on Pulmonary Hypertension. Eur Respir J. 2019;53.

3. Kovacs G, Berghold A, Scheidl S, et al. Pulmonary arterial pressure during rest and exercise in healthy subjects: a systematic review. Eur Respir J. 2009;34:888-94.

4. Hoeper MM, Bogaard HJ, Condliffe R, et al. Definitions and diagnosis of pulmonary hypertension. J Am Coll Cardiol. 2013;62: D42-50.

5. Rosenkranz S, Gibbs JS, Wachter R, et al. Left ventricular heart failure and pulmonary hypertension. Eur Heart J. 2016;37:942-54.

6. Wood P. Pulmonary hypertension with special reference to the vasoconstrictive factor. Br Heart J. 1958;20:557-70.

7. Vachiery JL, Tedford RJ, Rosenkranz S, et al. Pulmonary hypertension due to left heart disease. Eur Respir J. 2019;53(1):1801897. https://doi.org/10.1183/13993003.01897-2018 Published 24 January 2019 . The latest review of the pulmonary hypertension due to left heart disease at the 6th World Symposium on Pulmonary Hypertension.

8. Guazzi M, Arena R. Pulmonary hypertension with left-sided heart disease. Nat Rev Cardiol. 2010;7:648-59.

9. Garbi M, Chambers J, Vannan MA, et al. Valve stress echocardiography: a practical guide for referral, procedure, reporting, and clinical implementation of results from the HAVEC group. JACC Cardiovasc Imaging. 2015;8:724-36.

10. Picano E, Pibarot $P$, Lancellotti $P$, et al. The emerging role of exercise testing and stress echocardiography in valvular heart disease. J Am Coll Cardiol. 2009;54:2251-60.

11. Pierard LA, Lancellotti P. Stress testing in valve disease. Heart. 2007;93:766-72.

12. McMurray JJ, Adamopoulos S, Anker SD, et al. ESC guidelines for the diagnosis and treatment of acute and chronic heart failure 2012: the Task Force for the Diagnosis and Treatment of Acute and Chronic Heart Failure 2012 of the European Society of Cardiology. Developed in collaboration with the Heart Failure Association (HFA) of the ESC. Eur Heart J. 2012;33:1787-847.

13. Vachiery JL, Adir Y, Barbera JA, et al. Pulmonary hypertension due to left heart diseases. J Am Coll Cardiol. 2013;62:D100-8.

14. Bermejo J, Yotti R, Garcia-Orta R, et al. Sildenafil for improving outcomes in patients with corrected valvular heart disease and persistent pulmonary hypertension: a multicenter, double-blind, randomized clinical trial. Eur Heart J. 2018;39:1255-64.
15. Kapoor N, Varadarajan P, Pai RG. Echocardiographic predictors of pulmonary hypertension in patients with severe aortic stenosis. Eur J Echocardiogr. 2008;9:31-3.

16. Lancellotti P, Magne J, Donal E, et al. Determinants and prognostic significance of exercise pulmonary hypertension in asymptomatic severe aortic stenosis. Circulation. 2012;126:851-9.

17.• Nishimura RA, Otto CM, Bonow RO, et al. 2017 AHA/ACC focused update of the 2014 AHA/ACC guideline for the management of patients with valvular heart disease: a report of the American College of Cardiology/American Heart Association task force on clinical practice guidelines. J Am Coll Cardiol. 2017;70:252-89 Guideline for valvular heart disease by American Heart Association and American College of Cardiology.

18.• Baumgartner H, Falk V, Bax JJ, et al. 2017 ESC/EACTS guidelines for the management of valvular heart disease. Eur Heart J. 2017;38: 2739-91 Guideline for valvular heart disease by European Society of Cardiology and European Association for CardioThoracic Surgery.

19. Nishimura RA, Otto CM, Bonow RO, et al. 2014 AHA/ACC guideline for the management of patients with valvular heart disease: a report of the American College of Cardiology/American Heart Association Task Force on Practice Guidelines. Circulation. 2014;129:e521-643.

20. Lancellotti P, Pellikka PA, Budts W, et al. The clinical use of stress echocardiography in non-ischaemic heart disease: recommendations from the European Association of Cardiovascular Imaging and the American Society of Echocardiography. Eur Heart J Cardiovasc Imaging. 2016;17:1191-229.

21. Iung B, Vahanian A. Epidemiology of acquired valvular heart disease. Can J Cardiol. 2014;30:962-70.

22. Pasca I, Dang P, Tyagi G, et al. Survival in patients with degenerative mitral stenosis: results from a large retrospective cohort study. J Am Soc Echocardiogr. 2016;29:461-9.

23. Abramowitz Y, Jilaihawi $\mathrm{H}$, Chakravarty $\mathrm{T}$, et al. Mitral annulus calcification. J Am Coll Cardiol. 2015;66:1934 41.

24. Guerrero M, Dvir D, Himbert D, et al. Transcatheter mitral valve replacement in native mitral valve disease with severe mitral annular calcification: results from the first multicenter global registry. JACC Cardiovasc Interv. 2016;9:1361-71.

25. Magne J, Pibarot P, Sengupta PP, et al. Pulmonary hypertension in valvular disease: a comprehensive review on pathophysiology to therapy from the HAVEC group. JACC Cardiovasc Imaging. 2015;8:83-99.

26. Magne J, Lancellotti P, Pierard LA. Exercise pulmonary hypertension in asymptomatic degenerative mitral regurgitation. Circulation. 2010;122:33-41.

27. Magne J, Lancellotti P, O'Connor K, et al. Prediction of exercise pulmonary hypertension in asymptomatic degenerative mitral regurgitation. J Am Soc Echocardiogr. 2011;24:1004-12.

28. Le Tourneau T, Richardson M, Juthier F, et al. Echocardiography predictors and prognostic value of pulmonary artery systolic pressure in chronic organic mitral regurgitation. Heart. 2010;96:1311-7.

29. Ghoreishi M, Evans CF, DeFilippi CR, et al. Pulmonary hypertension adversely affects short- and long-term survival after mitral valve operation for mitral regurgitation: implications for timing of surgery. J Thorac Cardiovasc Surg. 2011;142:1439-52.

30. Michler RE, Smith PK, Parides MK, et al. Two-year outcomes of surgical treatment of moderate ischemic mitral regurgitation. $\mathrm{N}$ Engl J Med. 2016;374:1932-41.

Publisher's Note Springer Nature remains neutral with regard to jurisdictional claims in published maps and institutional affiliations. 